\title{
Alteraciones Morfológicas del Bazo de Ratas (Rattus norvergicus), Tratadas con Trióxido de Arsénico
}

\author{
Morphological Alterations of the Spleen of Rats \\ (Rattus norvegicus) Treated with Arsenic Trioxide
}

Alfaro-Burgos, $\mathbf{S}$.

ALFARO-BURGOS, S. Alteraciones morfológicas del bazo de ratas (Rattus norvergicus), tratadas con trióxido de arsénico. Int. J. Morphol., 31(3):1012-1019, 2013.

RESUMEN: En América Latina la presencia del arsénico en el ambiente y en las fuentes de agua para consumo humano, se debe a factores naturales de origen geológico como a actividades antropogénicas. El arsénico en las aguas naturales se encuentra principalmente como trivalente (arsenito) o pentavalente (arsenato). El objetivo de este trabajo fue determinar las alteraciones que provoca el trióxido de arsénico a nivel de la morfología del bazo de ratas (Rattus norvegicus - Sprague-Dawley). Se utilizaron 24 ratas de ambos sexos de 55 días de vida. Las ratas fueron pesadas y divididas en 3 grupos (4 hembras y 4 machos). Los grupos tratados fueron inyectados con $5 \mathrm{mg}$ y $10 \mathrm{mg}$ de $\mathrm{As}_{2} \mathrm{O}_{3}$ respectivamente, en dosis única diaria vía intraperitoneal por 15 días. Al grupo control se le aplicó agua destilada sin arsénico. Después del tratamiento los animales fueron sacrificados por eutanasia convencional y se obtuvo el bazo, los cuales fueron lavados, pesados y seccionados en cuatro partes, que fueron fijadas en formol tamponado al 10\%. Mediante técnica histológica se obtuvieron 4 muestras seriadas de cada bazo, de $5 \mu \mathrm{m}$ de espesor con una separación de $100 \mu \mathrm{m}$ entre si. Posteriormente fueron teñidas con H-E. Se analizaron 30 campos (120 campos por órgano). Los datos obtenidos permiten concluir que ratas tratadas con trióxido de arsénico, presentan alteración a nivel de los compartimentos del bazo, con un aumento del compartimento de la pulpa roja, una depleción en el tamaño y número de folículos linfoides y de la zona marginal. A su vez, se observó pérdida de la celularidad de la vaina linfoide periarteriolar (PALS).

PALABRAS ClAVE: Bazo; Trióxido de arsénico; Pulpa blanca; Pulpa roja; Rattus norvegicus.

\section{INTRODUCCIÓN}

El arsénico se encuentra ampliamente distribuido en nuestro entorno, de manera que la exposición humana al arsénico es inevitable. La exposición de la población en general, a varias especies de arsénico (inorgánico y orgánico) varía según la geoquímica local y el nivel de actividad antropogénica. Generalmente, el arsénico se presenta en cantidades muy pequeñas, encontrándose en las rocas, el suelo, el agua e incluso en suspensión. Estudios recientes revelan un efecto adverso importante en la salud de las personas que han sufrido una exposición prolongada, e incluso a concentraciones bajas de arsénico (Petrusevski et al., 2007).

La mayor amenaza para la salud pública proviene del consumo de agua potable, con bajas concentraciones de arsénico inorgánico. La Organización Mundial de la Salud, estableció un límite máximo de arsénico presente en el agua potable de 0,01 mg/L, límite máximo establecido también en Chile (INN, 2005). Esta norma rige también en la Comunidad Europea y en los Estados Unidos (EPA, 2001).
La exposición crónica a compuestos de arsénico inorgánico a través del agua potable y su inhalación se han asociado a trastornos y neoplasias en múltiples órganos (Patterson et al., 2004).

Aproximadamente, 1 de cada 100 personas que beben agua de manera prolongada con una concentración de arsénico superior a $0,05 \mathrm{mg} / \mathrm{L}$, posiblemente muera de un cáncer asociado a la toxicidad producida por el arsénico. Esta proporción puede ascender hasta el $10 \%$ si las concentraciones sobrepasan los $0,5 \mathrm{mg} / \mathrm{L}$ (Smith et al., 2000).

En la Región de Arica y Parinacota, en el norte de Chile, el arsénico es un contaminante común en los distintos sustratos. Bundschuh et al. (2008), determinaron rangos de arsénico para las aguas de la Quebrada de Camarones de 1000 a $5100 \mu \mathrm{g} / \mathrm{L}$, para el Valle de Lluta entre 30 a $280 \mu \mathrm{g}$ / L y para el Valle de Azapa de $20 \mu \mathrm{g} / \mathrm{L}$. 
El arsénico inorgánico puede presentarse en el ambiente de varias formas y con diferentes valencias; en las aguas naturales se encuentra principalmente como trivalente, como arsenito (III) o pentavalente como arsenato (V) (Brown et al., 1990). Los compuestos de arsénico inorgánico en los que el arsénico está presente en la forma trivalente, como el trióxido de arsénico (As2O3), son muy tóxicos (Chappell et al., 1999).

La exposición al arsénico inorgánico se asocia al desarrollo de enfermedad vascular periférica, cáncer a la piel, pulmón, hígado, vejiga, riñón y próstata (Abernathy et al., 1999; Christensen \& Poulsen, 1994; Cuzick et al., 1992; Rahman et al., 1996; Ryan et al., 2000), a la atrofia del timo (Drela, 2006; Alfaro-Burgos \& Valenzuela-Estrada, 2012), así como, a la depresión de la médula ósea con manifestación de anemia y leucopenia (Armstrong et al., 1984).

Aso \& Abiko (1978), demostraron que después de la implantación subcutánea de trióxido de arsénico en ratas, existía un alto contenido de arsénico a nivel de glóbulos rojos y bazo que se mantuvo elevado hasta el final del experimento. Bishayi \& Sengupta (2003), determinaron un retraso en el aclaramiento bacteriano a nivel del bazo en ratones tratados con arsénico respecto a los animales control, poniendo de manifiesto un estado inmunocomprometido después de la exposición al metal pesado.

El bazo se compone de dos compartimentos funcional y morfológicamente diferentes: la pulpa roja y la pulpa blanca, esta última, se haya compuesta por tres subcompartimentos: la vaina linfoide periarteriolar (PALS), el folículo linfoide y la zona marginal (Cesta, 2006).

El bazo combina el sistema inmune innato y adaptativo de una forma única y organizada, que permite eliminar los glóbulos rojos defectuosos de la circulación y conduce a la eliminación eficiente de los microorganismos y restos celulares transmitidos por la sangre. Esta función, hace del bazo, el órgano más importante de la reactividad inmunológica antibacteriana y antifúngica (Mebius \& Kraal, 2005).

Los cambios típicos que se pueden observar en el bazo cuando está expuesto a un agente inmunomodulador, se relacionan directamente con alteración en su tamaño, y una variación en el número de folículos con centros germinales (Kuper et al., 2000). Germolec et al. (2004), también señalan que los cambios en la celularidad del folículo linfoide es un predictor sensible de una inmunotoxicidad potencial. Más aun, debido a la presencia de linfocitos B y $\mathrm{T}$, los efectos inmunotóxicos de xenobióticos o sus metabolitos, se pueden reflejar en este órgano (Elmore, 2006).
Este estudio tuvo como objetivo determinar el daño morfológico que se presenta en los diferentes compartimentos del bazo cuando está expuesto al trióxido de arsénico.

\section{MATERIAL Y MÉTODO}

Se utilizaron 24 ratas (hembras y machos) SpragueDawley de 55 días de vida, las cuales fueron separadas en 3 grupos de 8 animales (cuatro machos y cuatro hembras), la manutención, manipulación y procedimientos aplicados en los animales experimentales, se realizó de acuerdo a las exigencias de uso de animales de laboratorio y contó con la aprobación del Comité de Ética/Bioética de la Universidad de Tarapacá (Arica, Chile).

La administración del trióxido de arsénico se aplicó en dosis única diaria, vía intraperitoneal (i.p.) por un período de 15 días. La solución de trióxido de arsénico se obtuvo a partir de arsénico comercial (Merck, Titrisol ${ }^{\circledR}$ ). A los grupos tratados se les aplicaron dosis de $5 \mathrm{mg}$ de As $2 \mathrm{O} 3$ por $\mathrm{kg}$ de peso corporal y de $10 \mathrm{mg}$ de $\mathrm{As}_{2} \mathrm{O}_{3}$ por $\mathrm{kg}$ de peso corporal. Al grupo control solo se le aplicó agua destilada sin arsénico (Patlolla \& Tchounwou, 2005).

Los animales fueron pesados diariamente y se mantuvieron en jaulas acondicionadas con libre disposición al alimento y agua. Luego de 15 días de tratamiento los animales fueron pesados y sacrificados por eutanasia según estándares convencionales. Mediante incisión abdominal, se retiró el bazo de los animales. Posteriormente los órganos fueron lavados con suero fisiológico y pesados, para luego ser fijados en formol tamponado al $10 \%$. Luego deshidratados en una batería de alcoholes de concentración creciente y colocados en xilol para ser incluidos en parafina (Martínez et al., 2011). Previo a la inclusión, el bazo fue seccionado en cuatro porciones, ubicando dos trozos perpendiculares a los otros dos dentro del molde de parafina, de manera de obtener cortes longitudinales y transversales del órgano en estudio. Los órganos en bloques de parafina fueron seccionados con micrótomo, obteniéndose cortes seriados de $5 \mu \mathrm{m}$ de espesor. En total se obtuvieron 4 cortes de cada bazo con una separación de $100 \mu \mathrm{m}$ entre si. Finalmente las muestras fueron teñidas con $\mathrm{H}$-E siguiendo los protocolos para una tinción estándar. Por cada muestra histológica se observó un número de 30 campos (120 campos por órgano). El análisis histológico y registro fotográfico se realizó utilizando un microscopio de luz (Olympus CX-31) con cámara digital Moticam 1000 (1.3 Mpixel USB 2.0). Se determinó el tamaño de pulpa blanca (zona marginal y folículo linfoide) y pulpa roja, mediante el programa Moticam 1000 con objetivo de 4x. 
Para el análisis de los datos, se realizó una prueba de normalidad, aplicando el Test de Shapiro-Wilks, con un $n=24$ (12 ratas machos y 12 hembras). Posteriormente se utilizó la prueba de Varianza (ANOVA) para determinar diferencias significativas $(\mathrm{p} \leq 0,05)$, entre las medias de los diferentes tratamientos experimentales. Para separar las medias, se hizo un análisis de Comparaciones Múltiples de Mínima Diferencia Significativa, $(\mathrm{p} \leq 0,05)$. Para separar las medias del peso del bazo, se aplicó el Test de Comparación Múltiple de Dunn's $(\mathrm{p} \leq 0,05)$. Se utilizó el software Statgraphic (versión 10.0).

\section{RESULTADOS}

Efecto del trióxido de arsénico en el peso del bazo. En las ratas tratadas con $10 \mathrm{mg}$ de arsénico, tanto en las hembras (Fig 1a) como en los machos (Fig. 1b) se presentó un aumento significativo del peso del bazo respecto al grupo control.
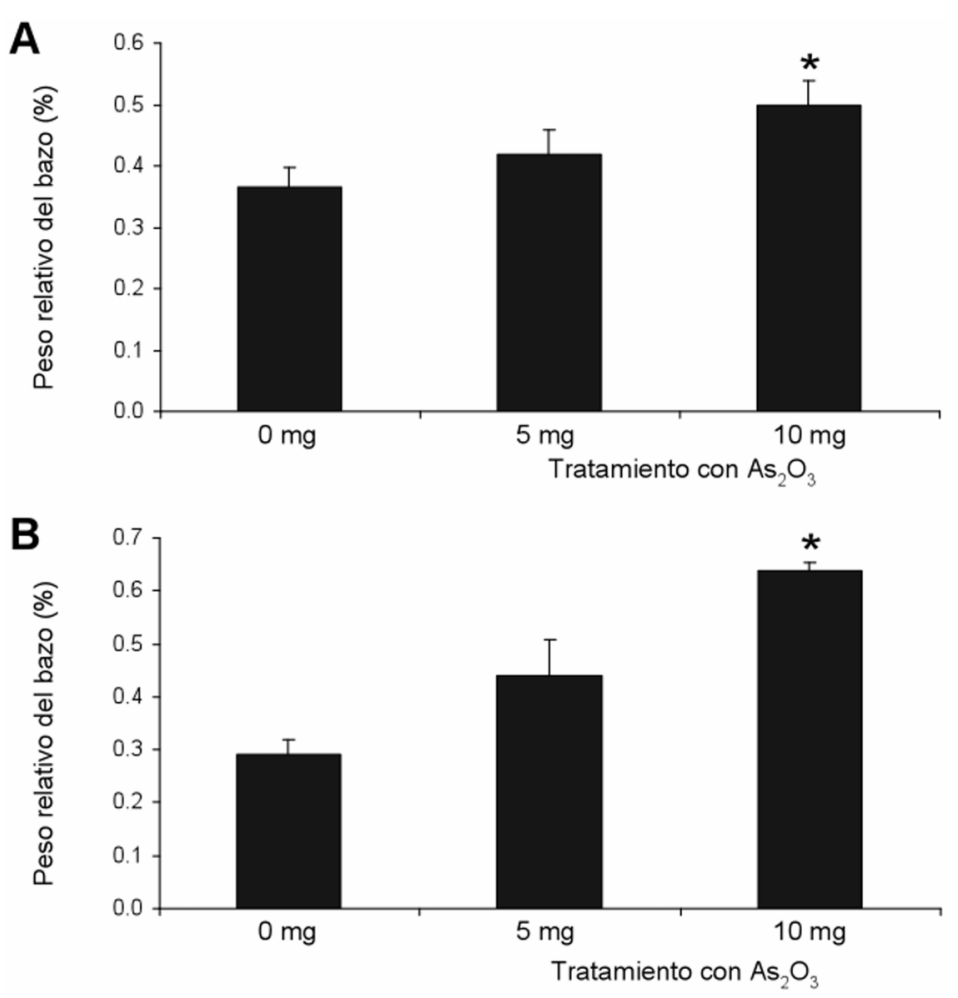

Fig. 1. Efecto del trióxido de arsénico en el peso del bazo en ratas hembras (1a) y machos (1b) control y tratadas. Se muestra la variación del peso relativo del bazo (relación peso bazo/peso corporal) de las ratas sometidas a diferentes concentraciones de arsénico. El (*) indica diferencias estadísticamente significativas respecto al grupo control, $(\mathrm{p} \leq 0,05)$.
Efecto del trióxido de arsénico a nivel de pulpa roja y pulpa blanca. En las ratas tratadas con dosis de 5 y $10 \mathrm{mg}$ de trióxido de arsénico, tanto en hembras (Fig. 2a) como en machos (Fig. 2b), se observó un aumento significativo del tamaño de la pulpa roja en relación con el grupo control. Respecto a la pulpa blanca, los resultados muestran una reducción significativa de tamaño de este compartimento en las ratas hembras tratadas con $10 \mathrm{mg}$ de arsénico. En las ratas machos esta disminución de tamaño fue significativa en los grupos tratados con 5 y $10 \mathrm{mg}$ de trióxido de arsénico respecto al grupo control.

Variación de tamaño del folículo linfoide y zona marginal en relación a la pulpa roja. En la Fig. 3a, se observa el tamaño (área de tejido en mm2) de los compartimentos esplénicos de ratas hembras tratadas y control. Los datos muestran una reducción significativa del tamaño tanto del compartimento folicular como de la zona marginal en las ratas tratadas con $10 \mathrm{mg}$ de trióxido de arsénico respecto al grupo control. A su vez, se observó un aumento de tamaño significativo de la pulpa roja en ratas hembras tratadas con 5 y $10 \mathrm{mg}$ de $\mathrm{As}_{2} \mathrm{O}_{3}$ respecto al grupo control. En los machos (Fig. 3b), se muestra una disminución significativa del tamaño del compartimento folicular y zona marginal, en ambos grupos de ratas tratadas con arsénico (5 y $10 \mathrm{mg}$ ), en relación al grupo control. A su vez, la pulpa roja, presentó un aumento significativo de tamaño en ratas tratadas con 5 y $10 \mathrm{mg}$ de $\mathrm{As} 2 \mathrm{O} 3$ respecto al grupo control.

Análisis histopatológico del bazo. En la Fig. 4, se observa el parénquima esplénico del bazo de una rata hembra control. Se distingue la pulpa blanca (provista de folículos linfoides que se muestran intensamente teñidos con hematoxilina a causa de la heterocromatina densa de los núcleos de los numerosos linfocitos) y el centro germinativo. Rodeando a la arteriola central se encuentra la vaina linfoide periarteriolar o PALS. Se observan numerosos folículos, de tamaños variables, rodeados por la zona marginal de tonalidad más suave, debido a la presencia de macrófagos residentes. Tanto los folículos linfoides como la zona marginal y el PALS, constituyen la pulpa blanca. Rodeando la pulpa blanca se encuentra la pulpa roja muy rica en glóbulos rojos y otros tipos celulares, como células reticulares, dendríticas y macrófagos. En la Fig. 5, correspondiente a una rata macho tratado con $5 \mathrm{mg}$ de trióxido de arsénico, se observa atrofia folicular por pérdida de celularidad no observándose centros germinativos. La arteriola central 


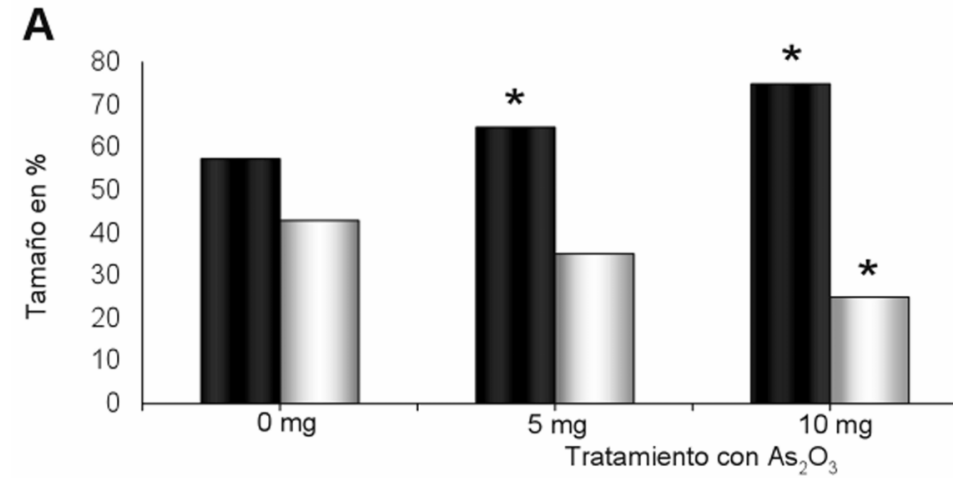

B

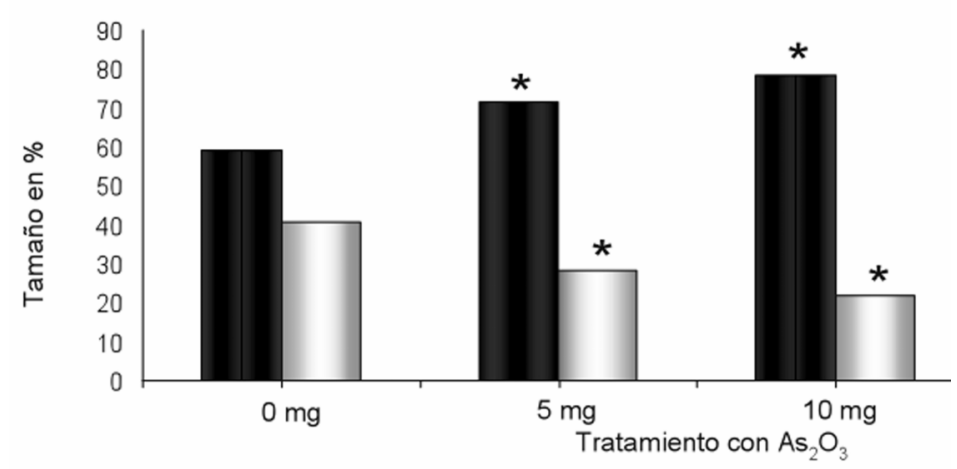

- Pulpa Roja $\quad$ P Pulpa Blanca
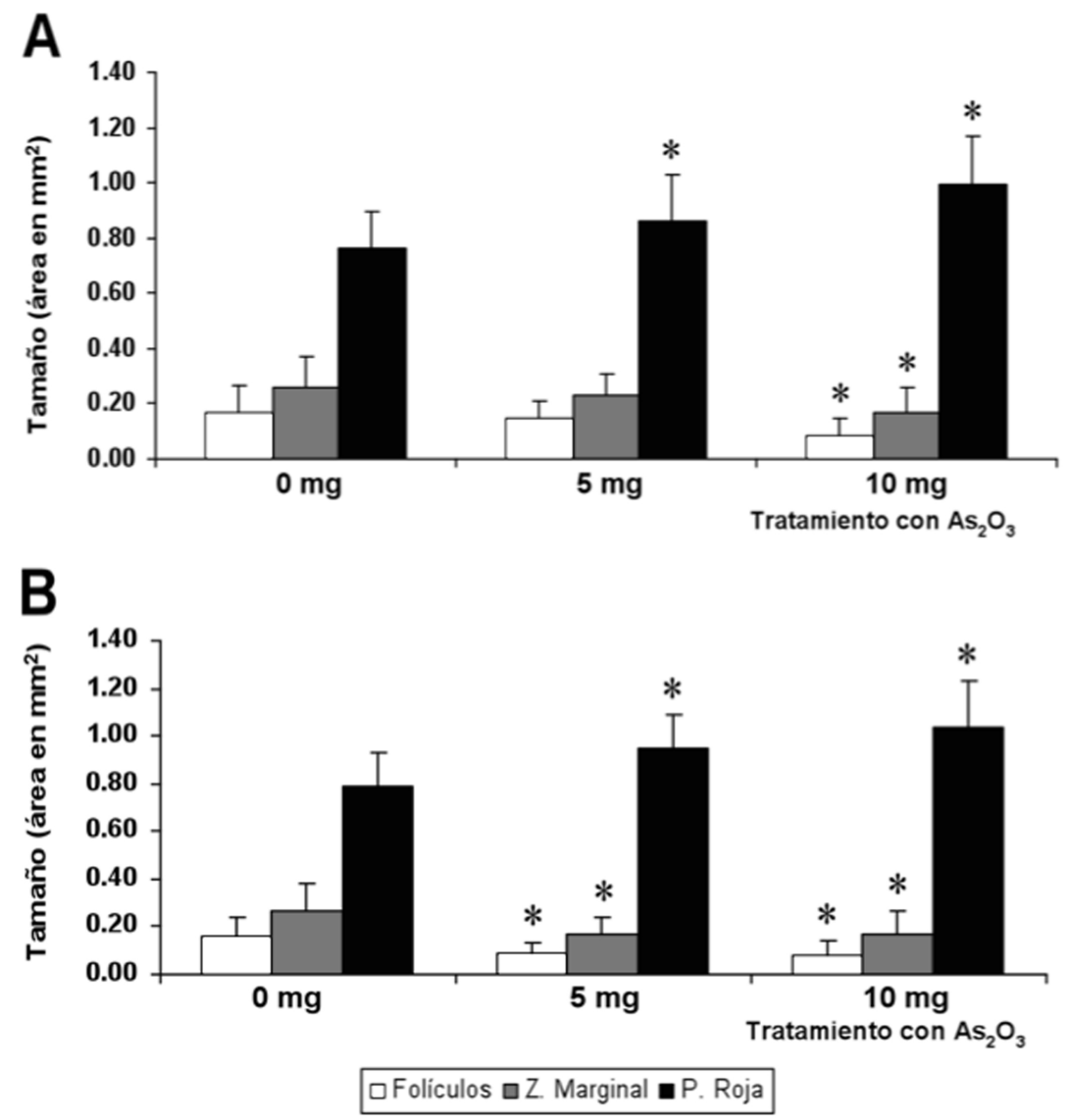

Fig. 2. Tamaño de pulpa roja y pulpa blanca del bazo en ratas hembras (2a) y machos (2b) control y tratadas. Se muestra el tamaño (en porcentaje) de la pulpa roja y pulpa blanca en ratas hembras y machos control y tratadas. El (*) indica diferencias estadísticamente significativas respecto al grupo control, $(\mathrm{p} \leq 0,05)$.
Fig. 3. Variación de tamaño de los compartimentos esplénicos en ratas hembras (3a) y machos (3b), sometidas a diferentes concentraciones de arsénico. Se muestra el tamaño del compartimento folicular, zona marginal y pulpa roja en ratas hembras y machos, control y tratadas con arsénico. El (*) indica diferencias estadísticamente significativas respecto al grupo control, $(\mathrm{p} \leq 0,05)$. 


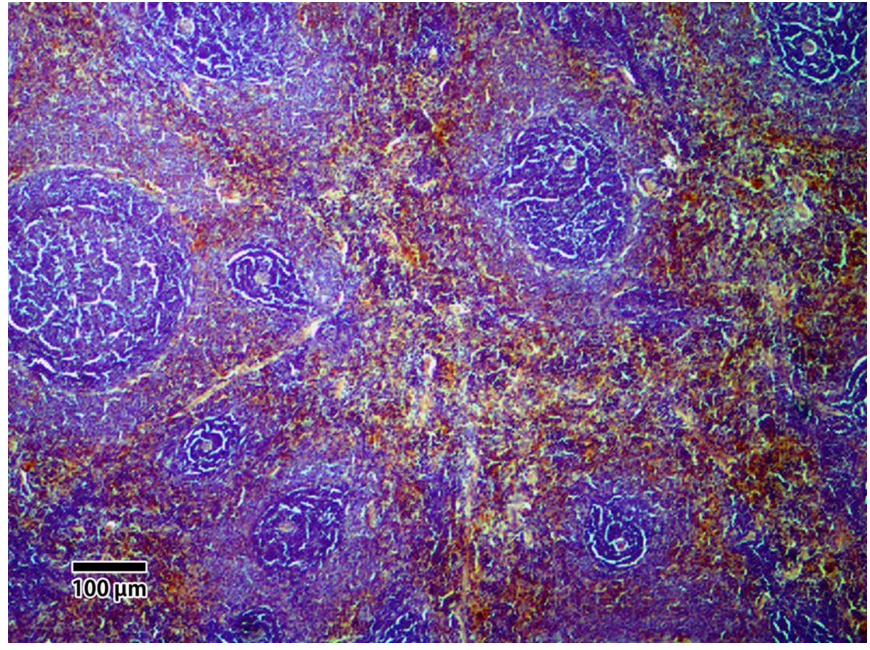

Fig. 4. Parénquima esplénico del bazo de una rata hembra control. H-E $($ Barra $=100 \mu \mathrm{m})$.

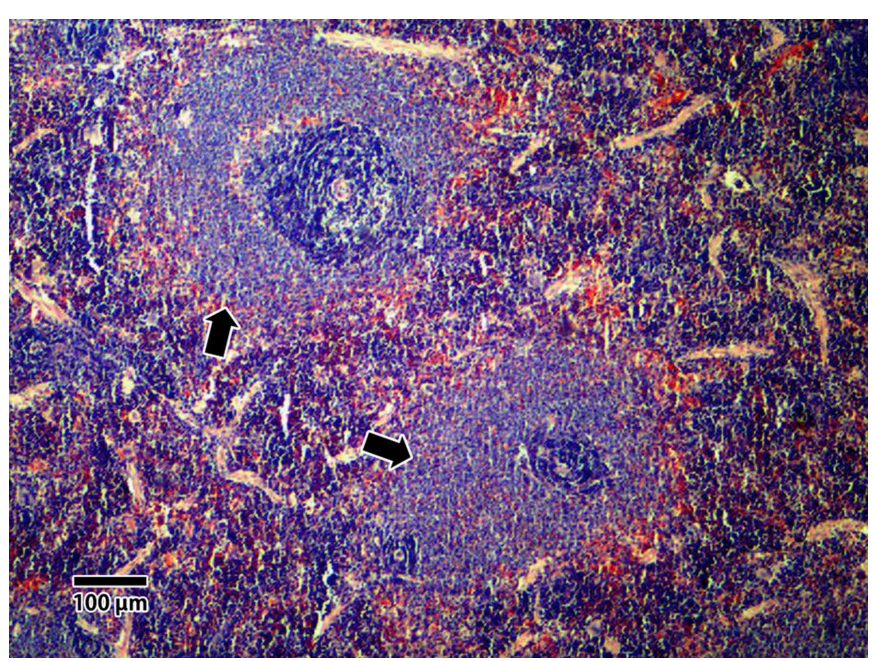

Fig. 5. Parénquima esplénico del bazo de una rata macho tratada con $5 \mathrm{mg}$ de trióxido de arsénico. Las flechas señalan la zona marginal de la pulpa blanca. H-E (Barra $=100 \mu \mathrm{m})$.

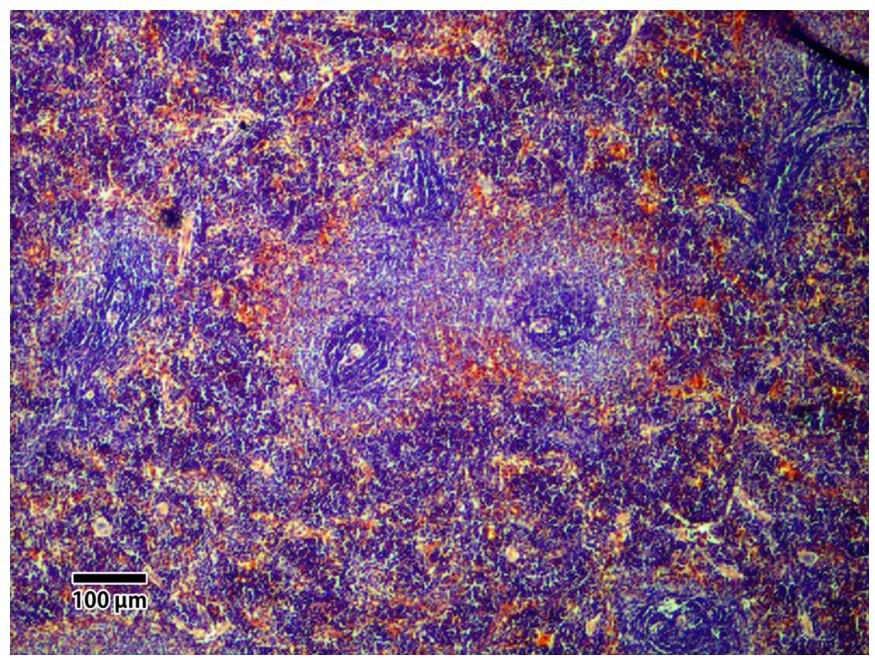

se encuentra rodeada por una escasa o nula vaina linfoide periarteriolar. La zona marginal (señalada con flechas) se observa en desproporción al tamaño de uno de los folículos. La Fig. 6, muestra el parénquima esplénico de una rata macho tratada con $10 \mathrm{mg}$ de arsénico. El análisis histopatológico de estos animales mostró un parénquima esplénico con una menor cantidad de folículos, y de un tamaño menor en comparación con las ratas control, predominando la pulpa roja.

\section{DISCUSIÓN}

Bailey et al. (2004), señalan que la comparación del peso del bazo en animales tratados con animales no tratados es a menudo complicado debido a las diferencias en los pesos corporales que pudiera existir entre los grupos. Por consiguiente, un parámetro que es conveniente utilizar para el análisis del peso del órgano, es la relación existente entre el peso del bazo/peso corporal del animal, que generalmente se describe como el peso relativo del órgano.

Los resultados muestran que el bazo de las ratas tratadas con $10 \mathrm{mg}$ de arsénico, tanto en ratas hembras como en machos, presenta un aumento de peso significativo respecto a las ratas control. Losco (1992), indicó que la relación peso bazo/peso corporal se mantiene constante, independiente de la edad y que en ratas normales es de alrededor del 0,20\%. Del mismo modo, Furrianca et al. (2008), en un estudio estereológico del bazo en ratas normales Sprague-Dawley, determinaron un peso relativo del bazo de $0,30 \%$.

En este estudio, el peso relativo del bazo de las ratas control coincide con el rango obtenido por ambos autores, lo que se expresa en un aumento significativo del peso del bazo en el grupo de ratas (hembras y machos) tratadas con $10 \mathrm{mg}$ de trióxido de arsénico.

Pfeiffer (1968) y Sellers et al. (2007), señalaron que las diferencias de peso entre los grupos de animales tratados y no tratados, son buenos indicadores para evaluar el efecto tóxico del compuesto de prueba. Además, Sellers et al., indican que el peso del bazo y del timo deben relacionarse con los resultados histopatológicos.

Los resultados observados en los compartimentos de pulpa roja y pulpa blanca en las ratas control (nor-

Fig. 6. Parénquima esplénico del bazo de una rata macho tratada con $10 \mathrm{mg}$ de trióxido de arsénico. H-E (Barra = $100 \mu \mathrm{m})$. 
males), muestran que ambos compartimentos se encuentran en proporciones similares a las reportadas por Furrianca et al., quienes determinan en ratas normales Sprague-Dawley una proporción de 54\% para la pulpa roja y un $42 \%$ para la pulpa blanca. En este trabajo los porcentajes para ratas hembras de pulpa roja fue de un $57 \%$ y de pulpa blanca un $42 \%$, en machos la pulpa roja fue de $59 \%$ y pulpa blanca $41 \%$.

En las ratas tratadas con 5 y $10 \mathrm{mg}$ de trióxido de arsénico se observó un notorio aumento del compartimento de la pulpa roja que probablemente ocurre a expensas del compartimento de la pulpa blanca, que disminuyó de tamaño. Los resultados muestran un aumento significativo del tamaño de la pulpa roja en los grupos de ratas tratadas con 5 y $10 \mathrm{mg}$ de arsénico, tanto en ratas hembras y machos con respecto al grupo control. Al contrario de lo ocurrido en la pulpa roja, la pulpa blanca disminuyó significativamente de tamaño, tanto en la ratas hembras tratadas con $10 \mathrm{mg}$ de arsénico, como en las ratas machos tratadas con 5 y $10 \mathrm{mg}$ de trióxido de arsénico.

Elmore, sugiere que en un estudio histopatológico del bazo es muy valioso medir el tamaño por separado de sus dos zonas funcionales, que son la pulpa roja hematógena y la pulpa blanca linfoide, con el fin de poder determinar diferencias de tamaño y de celularidad.

A su vez, Haley et al. (2005), recomiendan medir por separado el compartimento correspondiente a los folículos linfoides y zona marginal de la pulpa blanca, con el fin de evaluar los cambios de tamaño y de celularidad que pueden aumentar o disminuir en presencia de un agente inmunomodulador. En este trabajo, se midió por separado los compartimentos correspondientes a la pulpa blanca: folículo linfoide y zona marginal, para determinar si eran ambos o un compartimento el que disminuía de tamaño respecto al grupo control.

Los datos obtenidos, muestran una disminución significativa del tamaño del compartimento folicular, tanto en el grupo de ratas hembras tratadas con 10 mg de arsénico, como en los grupos de ratas machos tratadas con 5 y $10 \mathrm{mg}$ de arsénico. Estas diferencias de tamaño fueron significativas con respecto al grupo control.

Suttie (2006), indicó que la atrofia puede afectar a la pulpa blanca (folículos, zona marginal y/o PALS) y que este proceso de depleción puede relacionarse como un efecto directo del tratamiento aplicado. Por ejemplo, en un estudio realizado en ratones con metadona (AZT) se observó una disminución del tamaño de la pulpa blanca, con ausencia de folículos y disminución del PALS.
La zona marginal es una región única del bazo situada en la zona de transición de la pulpa roja y el folículo. Considerada por muchos autores como un compartimento separado y no como parte de la pulpa blanca. Está diseñada para detectar de la circulación sistémica, antígenos y patógenos, desempeñando un papel muy importante en el procesamiento de antígenos (Kuper et al., 2002).

Los resultados de la zona marginal, muestran que este compartimento disminuyó de tamaño junto con los folículos linfoides. En las hembras, la zona marginal presentó una disminución significativa de tamaño en el grupo de ratas tratadas con $10 \mathrm{mg}$ de arsénico respecto al grupo control. Del mismo modo, en el grupo de animales machos, se observó que ambos grupos experimentales (5 mg y $10 \mathrm{mg}$ de trióxido de arsénico) mostraron una reducción significativa del tamaño de la zona marginal respecto al grupo control. Idéntica situación fue observada por Elmore, en un tratamiento con N,N-dimetil-p-toluidina donde esta sustancia afectó los compartimentos de la pulpa blanca, produciendo una disminución de su tamaño y de su celularidad.

En consecuencia, el análisis de los datos evidencia que las ratas tratadas con trióxido de arsénico muestran una alteración a nivel de los compartimentos del bazo, presentando un aumento del compartimento de la pulpa roja, y una depleción en el tamaño y número de folículos linfoides y de la zona marginal. A su vez, se observa pérdida de celularidad de la vaina linfoide periarteriolar que probablemente afecte la función inmune del órgano esplénico.

ALFARO-BURGOS, S. Morphological alterations of the spleen of rats (Rattus norvegicus), treated with arsenic trioxide. Int. J. Morphol., 31(3):1012-1019, 2013.

SUMMARY: In Latin America, the presence of arsenic in the environment and water sources for human consumption is due to natural geological factors and anthropogenic activities. Arsenic in natural waters is mainly found as trivalent (arsenite) or pentavalent (arsenate). The aim of this study was to determine the alterations causing arsenic trioxide-level morphology of the spleen of rats (Rattus norvegicus - Sprague-Dawley). Were used 24 rats of both sexes of 55 days of life. The rats were weighed and divided into 3 groups ( 4 females and 4 males). The treated groups were injected with $5 \mathrm{mg}$ and $10 \mathrm{mg}$ of $\mathrm{As}_{2} \mathrm{O}_{3}$ respectively, intraperitoneally daily dosing for 15 days. The control group was administered arsenic-free distilled water. After treatment the animals were euthanized conventionally, and spleen was removed, which was washed, weighed and sectioned into four parts, which were fixed in $10 \%$ buffered formalin. Histological technique using four serial samples were obtained from each spleen of 5 microns thick with a spacing of 100 microns between them. Subsequently these were stained with $\mathrm{H}-\mathrm{E}$. We analyzed 30 fields ( 120 fields per organ). The data obtained indicates that rats treated with arsenic trioxide 
have an altered level of the compartments of the spleen, with an increased red pulp chamber, depletion in the size and number of lymphoid follicles and marginal zone. Furthermore, loss of cellularity of periarteriolar lymphoid sheath (PALS) was observed.

KEY WORDS: Spleen; Arsenic trioxide; White pulp; Red pulp; Rattus norvegicus.

\section{REFERENCIAS BILBIOGRÁFICAS}

Abernathy, C. O.; Liu, Y. P.; Longfellow, D.; Aposhian, H. V.; Beck, B.; Fowler, B.; Goyer, R.; Menzer, R.; Rossman, T.; Thompson, C. \& Waalkes, M. Arsenic: health effects, mechanisms of action, and research issues. Environ. Health Perspect., 107(7):593-7, 1999

Alfaro-Burgos, S. \& Valenzuela-Estrada, M. Effect on the Histological Structure of Thymus on Sprague-Dawley Treated with Arsenic Trioxide. Int. J. Morphol., 30(2):769-76, 2012.

Armstrong, C. W.; Stroube, R. B. \& Rubio, T. Outbreak of fatal arsenic poisoning caused by contaminated drinking water. Arch. Environ. Health, 39(4):276-9, 1984.

Aso, T. \& Abiko, Y. Tissue distribution of arsenic after subcutaneous implantation of arsenic trioxide pellet in rats. J. Toxicol. Sci., 3(2):109-15, 1978.

Bailey, S.; Zidell, R. \& Perry, R. Relationships Between Organ Weight and Body/Brain Weight in the Rat: What Is the Best Analytical Endpoint? Toxicol. Pathol., 32(4):448-66, 2004.

Bishayi, B. \& Sengupta, M. Intracellular survival of Staphylococcus aureus due to alteration of cellular activity in arsenic and lead intoxicated mature Swiss albino mice. Toxicology, 184(1):31-9, 2003.

Brown, R. M.; Newton, D. \& Pickford, C. J. Human metabolism of arsenobetaine ingested with fish. Hum. Exp. Toxicol., 9(1):41-6, 1990.

Bundschuh, J.; Nicolli, H. B.; Blanco, M. C.; Blarasin, M.; Farías, S. S. \& Cumbal, S. Distribución de arsénico en la región sudamericana. En: Bundschuh, J.; Pérez, A. \& Litter, M. (Eds.). Iberoarsen Distribución del arsénico en las regiones Ibérica e Iberoamericana. Buenos Aires, CYTED, 2008. pp.137-87.

Cesta, M. F. Normal Structure, Function, and Histology of the Spleen. Toxicol. Pathol., 34(5):455-65, 2006.

Chappell, W. R.; Abernathy, C. O. \& Calderon, R. L. Arsenic exposure and health effects. Proceeding of the Third International Conference on Arsenic Exposure and Health Effects, 14-18 July 1998, San Diego, California. S.I., 1999.

Christensen, J. M. \& Poulsen, O. M. A 1982 - 1992 Surveillance Programme on Danish pottery painters. Biological levels and health effects following exposure to soluble or insoluble cobalt compounds in cobalt blue dyes. Sci. Total Environ., 150(13):95-104, 1994.

Cuzick, J.; Sasieni, P. \& Evans, S. Ingested arsenic, keratoses, and bladder cancer. Am. J. Epidemiol., 136(4):417-21, 1992.

Drela, N. Xenobiotic-induced alterations in thymocyte development. APMIS, 114(6):399-419, 2006.

Elmore, S. A. Enhanced Histopathology of the Spleen. Toxicol. Pathol., 34(5):648-55, 2006.

Enviromental Protection Agency (EPA). The arsenic and clarifications to compliance and new source contaminants monitoring final rule. Fed. Reg., 66:6976-7066, 2001.

Furrianca, M.; Vásquez, B. \& del Sol, M. Comparative Stereology between the spleen of the guinea pig (Cavia porcellus) and the rat (Rattus novergicus, Sprague Dawley). Int. J. Morphol., 26(3):529-32, 2008.

Germolec, D. R.; Kashon, M.; Nyska, A.; Kuper, C. F.; Portier, C.; Kommineni, C.; Johnson, K. A. \& Luster, M. I. The accuracy of extended histopathology to detect immunotoxic chemicals. Toxicol. Sci., 82(2):504-14, 2004.

Haley, P.; Perry, R.; Ennulat, D.; Frame, S.; Johnson, C.; Lapointe, J. M.; Nyska, A.; Snyder, P.; Walker, D.; Walter, G. \& STP Immunotoxicology Working Group. STP position paper: best practice guideline for the routine pathology evaluation of the immune system. Toxicol. Pathol., 33(3):404-8, 2005.

Instituto Nacional de Normalización (INN). Agua Potable. Parte 1, Requisitos. Norma Chilena Oficial, NCh 409/1.Of.84. Santiago, Ministerio de Salud, 2005.

Kuper, C. F.; Harleman, J. H.; Richter-Reichelm, H. B. \& Vos, J. G. Histopathologic approaches to detect changes indicative of immunotoxicity. Toxicol. Pathol., 28(3):454-66, 2000.

Kuper, D. F.; de Heer E.; Van Loveren H. \& Vos, J. G. Immune System. In: Haschek, W. M.; Rousseaux, C. G. \& Wallig. M. A. (Eds.). Handbook of Toxicologic Pathology. San Diego, Academic Press, 2002. pp.585-646.

Losco, P. Normal Development, Growth, and Aging of the Spleen. In: Mohr, U.; Dungworth, D. L. \& Capen, C. C. (Eds.). Pathobiology of the Aging Rat (Washington D.C., ILSI Press, 1992. pp.75-94.

Martínez, P.; Pina, A.; Soto, A. \& García, G. Comparación histológica e inmunohistoquímica de muestras de tejido procesadas por la técnica convencional o por la técnica simplificada de acetonas. Int. J. Morphol., 29(2):575-80, 2011.

Mebius, R. E. \& Kraal, G. Structure and function of the spleen. Nat. Rev. Immunol., 5(8):606-16, 2005. 
Patlolla, A. K. \& Tchounwou, P. B. Cytogenetic evaluation of arsenic trioxide toxicity in Sprague-Dawley rats. Mutat. Res., 587(1-2):126-33, 2005.

Patterson, R.; Vega, L.; Trouba, K.; Bortner, C. \& Germolec, D. Arsenic-induced alterations in the contact hypersensitivity response in Balb/c mice. Toxicol. Appl. Pharmacol., 198(3):434-43, 2004.

Pfeiffer, C. J. A mathematical evaluation of the thymic weight parameter. Toxicol. Appl. Pharmacol., 13(2):220-7, 1968.

Petrusevski, B.; Sharma, S.; Schippers, J. S. \& Shordt, K. Arsenic in drinking water. International Water and Sanitation Centre. Oxford, IRC, 2007.

Rahman, M.; Wingren, G. \& Axelson, O. Diabetes mellitus among Swedish art glass workers An effect of arsenic exposure? Scand. J. Work Environ. Health, 22(2):146-9, 1996.

Ryan, P.; Huet, N. \& MacIntosh, D. Longitudinal investigation of exposure to arsenic, cadmium, and lead in drinking water. Environ. Health Perspect., 108(8):731-5, 2000.

Sellers, R. S.; Mortan, D.; Michael, B.; Roome, N.; Johnson, J.; Yano, B. L.; Perry, R. \& Schafer, K. Society of Toxicologic Pathology Position Paper: Organ Weight Recommendations for Toxicology Studies. Toxicol. Pathol., 35(5):751-5, 2007.

Smith, A. H.; Lingas, E. O. \& Rahman, M. Contaminación del agua de bebida con arsénico en Bangladesh: una emergencia de salud pública (resumen en español). Bull. World Health Organ., 78(9):1093-103, 2000.

Suttie, A. W. Histopathology of the Spleen. Toxicol. Pathol., 34(5):466-503, 2006.
Dirección para Correspondencia:

Prof. Mg. Sergio Alfaro Burgos

Departamento de Biología

Facultad de Ciencias

Universidad de Tarapacá

Casilla 7-D

General Velásquez 1775, Arica

CHILE

Teléfono: +56582205418

Fax: +56 582205381

Email: salfarob@uta.cl

Recibido : 21-01-2013

Aceptado: 19-05-2013 